be substantial due to the lack of routine testing for this pathogen in stool cultures, the absence of public health surveillance in many regions, and incomplete follow-up of infected children. Temporary exclusion of all children was an effective control strategy but further research is needed to determine the optimal intervention.

FROM: Belongia EA et al. JAMA 1993;269:883888.

\section{Wild Poliovirus Type 3 in Canada Linked to Outbreak in Netherlands}

From September 1992 to February 1993, 68 cases of poliomyelitis occurred among members of a religious community in the Netherlands. An investigation was conducted of members of an affiliated religious community in Alberta, Canada who had direct contact (ie, travel to and from the Netherlands) with members of the affected community. Wild poliovirus type 3 (PV3) of a strain virtually identical to the one that caused the outbreak in the Netherlands was isolated from stool specimens obtained from 21 (47\%) of 45 persons (primarily children). No cases of paralytic poliomyelitis have been identified in Canada since 1988; however, because the clinical to subclinical case ratio for PV3 infection may be as low as 1:1000, wild poliovirus can circulate in a population for several months before paralytic disease occurs.

The last outbreak of poliomyelitis in the United States occurred in 1979 when 10 paralytic cases were reported. That outbreak originated in the Netherlands in 1978 when poliovirus type 1 spread from the Netherlands to Canada and then to the United States, involving the same religious group.

Although efforts to protect religious communities that object to vaccination continue, success has been limited. Only global eradication of poliomyelitis-a health goal for the year 2000 adopted by the World Health Assembly in 1988-will ensure that poliovirus infection will not cause paralytic disease in the United States or the rest of the world.

FROM: The Centers for Disease Control and Prevention. M M WR 1993;42:338-339.

\section{Female Condom Approved by FDA}

The FDA has approved the first female condom for distribution in the United States. The condom, available from Wisconsin Pharmacal Co., will cost about $\$ 2.50$. The company said the polyurethane used to make the condom is stronger than the latex used in an ordinary male condom and is resistant to oils and oil-based lubricants. Acquired immunodeficiency syn- drome (AIDS) activists are pleased and believe that it will prevent transmission of HIV to women, especially those who are unable to insist that their partners wear condoms.

\section{C-Section Deliveries May Reduce Risk of HIV in Newborns}

Dr. Paolo Villari and colleagues at Harvard School of Public Health recently conducted a metaanalysis of studies on perinatal HIV infection and found that $20.2 \%$ of infants born by vaginal delivery to infected mothers became infected and only approximately $14 \%$ of the babies delivered by C-section were infected. They concluded that performing elective $\mathrm{C}$-sections in HIV-infected women is potentially an effective procedure to prevent HIV infection in newborns. These findings were distributed by the Online Journal of Current Clinical Trials.

\section{Long-Term Mortality After Transfusion-Associated Non-A, Non- B Hepatitis Similar to Mortality from All Causes}

Non-A, non-B hepatitis was recognized in the mid-1970s during the course of several prospective studies of transfusion-associated hepatitis. These studies found an incidence of hepatitis ranging from $7 \%$ to $17 \%, 78 \%$ to $92 \%$ of which represented non-A, non-B hepatitis. Initial concern about posttransfusion non-A, non-B hepatitis was limited because the acute illness seemed clinically mild and often was identified only because of serum enzyme monitoring. However, in later studies, half or more of affected patients continued to have increased aminotransferase activity more than six months after the initial illness. More disturbing have been the reports linking primary hepatocellular carcinoma with earlier bouts of transfusionassociated non-A, non-B hepatitis. Although chronic hepatitis, cirrhosis, and hepatocellular carcinoma now are accepted as sequelae, their frequency, rate of development, and the degree to which they contribute to mortality are not yet well established because current data come largely from retrospective studies.

Dr. Leonard B. Seeff and colleagues with the National Heart, Lung, and Blood Institute Study Group conducted a prospective study comparing the morbidity and mortality among patients who had received transfusions and in whom non-A, non-B hepatitis developed with those in matched control groups of persons who had received transfusions but did not develop hepatitis. After an average follow-up of 18 years, the estimated 
mortality from all causes was $51 \%$ for those with transfusion-associated non-A, non-B hepatitis, compared with $52 \%$ of the controls. In this long-term follow-up study, there was no increase in mortality from all causes after transfusion-associated non-A, non-B hepatitis, although there was a small but statistically significant increase in the number of deaths related to liver disease. In an accompanying editorial, Dr. Albert J. Czaja of the Mayo Clinic notes that the observations of Dr. Seeff et al "heighten our awareness of the disease potential of hepatitis $\mathrm{C}$ infection and provide a realistic hope that dire consequences are unusual."

FROM: Seeff LB, Buskell-Bales Z, Wright EC, et. al. Long-term mortality after transfusion-associated nonA, non-B hepatitis. N Engl J M ed 1992;327:1906-1911.

\section{Clinton Appoints First AIDS Czar}

President Clinton appointed Kristine Gebbie as the first national AIDS coordinator on the eve of dismantling the National AIDS Commission. Clinton said Gebbie would be a full member of the Domestic Policy Council and work closely with the Department of Health and Human Services in coordinating federal AIDS policies.

Gebbie currently serves as a special consultant to the Department of Health and Human Services, and prior to that, she was the administrator for the Oregon Health Division, secretary for the Washington State Department of Health, and a member of President Reagan's Commission on HIV. Since 1989, she also has served as chair of the Centers for Disease Control Advisory Committee for the Prevention of HIV.

On July 21 and 22, more than 50 activists and other representative from national organizations concerned with AIDS met with Kristine Gebbie's office to discuss the agenda and organization framework for consideration by Gebbie.

Although AIDS advocates had criticized the administration for the delay in filling the post, some praised Clinton for selecting Gebbie because of her long history in working to implement positive public health programs to combat HIV transmission and to serve the AIDS community.

\section{Healthcare Worker Reported Dead from Creutzfeldt- Jakob Disease}

A 58-year-old internist was reported to have died of Creutzfeldt-Jakob Disease (CJD). Symptoms of impaired mentation were reported first in May 1990, and within three months the patient died of progressive neurological disease. A brain biopsy revealed spongiform encephalopathy. The patient spent one year in pathology training in 1960 performing numerous postmortem examinations, raising suspicion of possible occupationally acquired infection. The authors of this article summarize 23 additional reported cases of CJD in healthcare workers, including five physicians (two neurosurgeons and a pathologist), four dentists, nine nurses, three nursing assistants, and two histopathology technicians.

CJD is a neurodegenerative disease of the brain characterized by rapidly progressive dementia resulting in death within one year of clinical onset. Because it can be transmitted by infected human tissue, concerns have been raised among healthcare workers about potential occupationally acquired infection.

CJD has a reported worldwide incidence of one to two cases per million population, although it is thought to be underdiagnosed. CJD is believed to be caused by "prions," transmissible agents apparently containing no nucleic acids, differing from all other transmissible agents. CJD also can be genetic in origin and between $5 \%$ and $15 \%$ of identified cases occur in an autosomal-dominant pattern associated with a specific genetic mutation. Neurological tissues also have been associated with transmission of the CJD pathogen, including growth hormone prepared from human pituitary glands and cadaveric dural grafts. The very long latency, which can exceed 30 years, makes it difficult to ascertain the source of infection in sporadic cases. 206. 